\title{
Comparison of Two Methods of Administering Bronchodilator Aerosol to Asthmatic Patients
}

\author{
Y. F. J. CHOO-KANG, I. W. B. GRANT
}

\section{Results}

After inhalation of salbutamol aerosol from pressurized canisters the mean pretreatment $\mathrm{FEV}_{1}$ in the 78 patients $(1.039 \mathrm{l})$ increased by 0.24 1. The mean increase in FEV $_{1}$ after I.P.P.V. administration was significantly larger $(P<0.001)$ : from a pretreatment level of 1.0441 the $\mathrm{FEV}_{1}$ increased by 0.361 . The response to the two treatments according to initial levels of $\mathrm{FEV}_{1}$ are compared in the table. Except at the highest levels of pretreatment $\mathrm{FEV}_{1}$ the increase in $\mathrm{FEV}_{1}$ was always greater after I.P.P.V., and the superiority of I.P.P.V. was inversely related to the pretreatment level of $\mathrm{FEV}_{1}$. with that recorded after the inhalation of a conventional dose $(200 \mu \mathrm{g})$ from a pressurized canister. The mean increase was significantly greater after I.P.P.V. administration, and the superiority of this method was greatest in patients with the lowest pretreatment FEV

\section{Introduction}

Sympathomimetic bronchodilators such as isoprenaline, salbutamol, and terbutaline are effective in relieving bronchospasm. When inhaled in aerosol form these act rapidly, and their effective dose is much smaller than by mouth. The degree of response may, however, be limited by the patient's ability to inhale an adequate dose of the drug from the apparatus delivering the aerosol. The bronchodilator response also tends to decline with increasing severity of bronchospasm, ${ }^{1}$ and a larger dose of the drug may be indicated. In patients with moderate or severe asthma an efficient method of administering an adequate dose is clearly needed. Dyspnoeic patients can seldom inhale such a dose from a pressurized canister, and the administration of an aqueous aerosol by intermittent positivepressure ventilation (I.P.P.V.) would seem to be a more efficient method of delivering a large dose of bronchodilator to the bronchi. Unlike Cohen and $\mathrm{Hale}^{2}$ we have found I.P.P.V. more effective than the inhalation of a bronchodilator aerosol from a pressurized canister, and we report here a comparative study of these two methods of treatment in asthmatic patients.

\section{Patients and Methods}

The forced expiratory volume in one second $\left(\mathrm{FEV}_{1}\right)$ was measured in patients with chronic asthma before and 45 minutes after the inhalation of $200 \mu \mathrm{g}$ of salbutamol from a pressurized canister (Ventolin inhaler). The same patients also received $10 \mathrm{mg}$ of salbutamol (as a $0.5 \%$ aqueous aerosol) delivered by I.P.P.V. from a Bennett ventilator, and $\mathrm{FEV}_{1}$ was measured as before. The treatments were given in random order and each was given on a separate day.

Patients were included in the analysis only if the pretreatment values of $\mathrm{FEV}_{1}$ for the two treatments did not differ by more than $200 \mathrm{ml}$, the percentage increase in $\mathrm{FEV}_{1}$ above pretreatment value was at least $20 \%$ for one of the two treatments, and the absolute increase in $\mathrm{FEV}_{1}$ was at least $200 \mathrm{ml}$. Thirty-eight men and 40 women aged 22 to 85 (mean 57) years with reversible airways obstruction fulfilled these criteria. Sixty-eight of the patients were treated with prednisolone by mouth during the period of assessment.

Respiratory Unit, Northern General Hospital, Edinburgh EH5 $2 D Q$

Y. F. J. CHOO-KANG, M.B., M.R.C.P., Senior Registrar (present appointY. F. J. Consultant Physician, Cameron Hospital, Windygates, Fife) I. W. B. GRANT, M.B., F.R.C.P., Consultant Physician

\section{Discussion}

It is always difficult to compare the effects of bronchodilator drugs because of the many factors which may influence the response to these agents, perhaps the most important of which is the state of the patient's asthma. Hume and Gandevia' ${ }^{1}$ have shown that patients' responses are directly related to the severity of their asthma. Differences in response to bronchodilator aerosols may thus be related entirely to variations in the severity of asthma. Nevertheless, our results with I.P.P.V. show that we have a method of administering a bronchodilator aerosol which is significantly more effective than inhalation from a pressurized canister in the conventional dosage. Perhaps even more important is our observation that the superiority of I.P.P.V. administration was greatest in patients with the lowest pretreatment levels of $\mathrm{FEV}_{1}$. Such patients, who might have been regarded as "bronchodilator-resistant" in terms of their response to salbutamol inhaled from a pressurized canister, often improved dramatically when an aqueous aerosol was administered by I.P.P.V. We have found that this form of treatment, used in conjunction with large oral or intravenous doses of corticosteroids, has controlled status asthmaticus in many patients who might otherwise have needed orotracheal intubation, mechanical ventilation, and bronchial lavage.

Possibly the greater efficacy of I.P.P.V. administration in this study was simply dose-related, but Shenfield et al. ${ }^{3}$ have shown that only $10-15 \%$ of a dose delivered by I.P.P.V. is absorbed as compared with almost $100 \%$ of the same dose inhaled from a pressurized canister by a patient experienced in this technique. ${ }^{4}$ Thus, for a valid comparison of these two methods of administration it would be necessary to use a dose of 1.0-1.5 mg (10-15 metered doses of $100 \mu \mathrm{g}$ ) by inhalation to match the 10-mg dose delivered by I.P.P.V. The suggestion that any patient should be asked to inhale 10-15 doses at a time, however, might be unacceptable to many respiratory physicians, and patients with fairly severe asthma might not be capable of inhaling efficiently so many doses in rapid succession. More recently Shenfield et al. ${ }^{5}$ have claimed that the administration of an aqueous salbutamol aerosol by I.P.P.V. is no more effective than the inhalation of the same dose from a Wright's nebulizer, but they concede that I.P.P.V. may have some additional advantage in patients with status asthmaticus.

Sympathomimetic bronchodilator aerosols have been implicated in the increased death rate from asthma during 1960-66, ${ }^{6-8}$ but salbutamol in the dose we administered by I.P.P.V. causes no serious side effects when given to hypoxic patients in status asthmaticus. ${ }^{\circ}$ We conclude therefore that the administration of a $0.5 \%$ salbutamol aerosol by I.P.P.V. is a safe and effective measure for the rapid relief of severe bronchospasm. 
Percentage Increase in FEV 1 after Administration of Salbutamol Aerosol by I.P.P.V. or Inhalation according to Pretreatment FEV 1

\begin{tabular}{|c|c|c|c|c|c|c|}
\hline Pretreatment FEV 1 (1) & $<0 \cdot 75$ & $0 \cdot 75-$ & $1 \cdot 0-$ & $1 \cdot 25-$ & $\geqslant 1.5$ & Mean \\
\hline $\begin{array}{l}\text { No. of patients } \\
\% \text { Increase in } \mathrm{FEV}_{1} \text { after: } \\
\text { I.P.P.V. } \\
\text { Inhalation }\end{array}$ & $\begin{array}{l}13 \\
42 \cdot 5 \\
18 \cdot 2\end{array}$ & $\begin{array}{l}26 \\
32 \cdot 5 \\
23 \cdot 5\end{array}$ & $\begin{array}{l}18 \\
36 \cdot 5 \\
20 \cdot 8\end{array}$ & $\begin{array}{l}12 \\
34 \cdot 4 \\
21 \cdot 6\end{array}$ & $\begin{array}{c}9 \\
32 \cdot 3 \\
32 \cdot 6\end{array}$ & $\begin{array}{l}34.48 \\
23.07\end{array}$ \\
\hline
\end{tabular}

We thank Mrs. Margaret Shotter for help with the statistical analysis, Miss Anthea Lints for recording the data, and Miss J. Williamson for typing the manuscript.

\section{References}

1 Hume, K. M., and Gandevia, B., Thorax, 1957, 12, 276.

2 Cohen, A. A., and Hale, F. C., American Fournal of the Medical Sciences, 1965, 249, 309.
3 Shenfield, G. M., et al., American Review of Respiratory Diseases, 1973, 108,501 .

4 Walker, S. R., et al., Clinical Pharmacology and Therapeutics, 1972, 13, 861 , vol. 13 .

5 Shenfield, G. M., Evans, M. E., and Paterson, J. W., British Fournal of Clinical Pharmacology, 1974, 1, 295.

6 Inman, W. H. W., and Adelstein, A. M., Lancet, 1969, 2, 279.

7 Speizer, F. E., et al., British Medical fournal, 1968, 1, 339

8 Stolley, P. D., American Review of Respiratory Diseases, 1972, 105, 883.

9 Choo-Kang, Y. F. J., Tribe, A. E., and Grant, I. W. B., Scottish Medical fournal, 1974, 19, 191.

\section{PRELIMINARY COMMUNICATIONS}

\section{Placental Scanning with Computer- linked Gamma Camera to Detect Impaired Placental Blood Flow and Intrauterine Growth Retardation}

\author{
W. R. CHATFIELD, T. G. H. ROGERS,
} B. E. W. BROWNLEE, P. E. RIPPON

British Medical fournal, 1975, 2, 120-122

\begin{abstract}
Summary
By retrospective analysis of 65 placental localization studies by a computer-linked gamma camera the isotope uptake patterns were correlated with the eventual outcome of the pregnancies. The uptakes by anterior and lateral placentae were reduced in pregnancies which resulted in growth-retarded babies and statistically unrelated to the gestation of the pregnancy. This simple representation of placental blood flow could be a clinically useful index of placental function.
\end{abstract}

\section{Introduction}

Current diagnosis and management of intrauterine growth retardation are based on the direct measurement of fetal growth by clinical examination and sonar cephalometry and the indirect measurement of placental function by determining its ability to produce enzymes and hormones. These techniques depend on an accurate estimate of the gestation of the pregnancy and require serial recordings to establish a definite diagnosis. No single test can predict accurately intrauterine malnutrition on one sampling.

\footnotetext{
Department of Obstetrics and Gynaecology, Christchurch Clinical School, University of Otago, Christchurch, New Zealand

W. R. CHATFIELD, M.D., F.R.C.S., Senior Lecturer

P. E. RIPPON, Technician

Christchurch Public Hospital, Christchurch, New Zealand

T. G. H. ROGERS, M.A., Senior Physicist, Department of Medical Physics B. E. W. BROWNLEE, M.D., F.R.A.C.P., Physician in Charge, Department of Nuclear Medicine
}

The amount of oxygen and calories delivered to the fetoplacental unit is limited primarily by the blood flow to the intervillous space. Though it is generally accepted that the placental blood flow is decreased in pregnancies in which intrauterine growth is retarded only a few studies have tried to substantiate this claim. Investigations have been limited to the clearance of ${ }^{22} \mathrm{Na}$ or ${ }^{24} \mathrm{Na}$ injected into either the intervillous space or the myometrium of affected women. ${ }^{1-3}$ These techniques are impracticable and hazardous and have never been used in the clinical diagnosis and management of intrauterine growth retardation. After experience with radioisotope uptake methods designed to localize the placental site recent studies $^{45}$ have attempted to obtain a functional index of placental flow from retrospective analysis of dynamic imaging of the placental site with ${ }^{9{ }^{9 m}} \mathrm{Tc}$ or ${ }^{113 \mathrm{~m}} \mathrm{I}$ using a gamma camera linked to a digital computer.

We present here a retrospective analysis of placental-site isotope uptake patterns using a computer-linked gamma camera. The analysed patterns were then correlated with the outcome of the pregnancies. Our aim was to determine whether this representation of blood flow through the placental site could provide a useful index of placental function to help in the diagnosis and management of intrauterine growth retardation.

\section{Patients and Methods}

Sixty-five placental-site isotope uptake patterns were studied. The placental localization studies had been requested for variable lie of the fetus in seven cases, a high presenting part in 10 , amniocentesis for Rhesus incompatibility in three, and amniocentesis to estimate fetal lung maturity in eight. Over half the studies, however, were in patients with antepartum haemorrhage (37 cases) as the diagnosis or exclusion of placenta praevia is the major clinical indication for placental localization. The recent indication to perform amniocentesis to estimate the phospholipid content of the liquor and hence fetal lung maturity has permitted the study of placental isotope uptake patterns in pregnancies with proved intrauterine growth retardation. In six pregnancies more than one study was performed.

\section{MEASUREMENT OF PLACENTAL ISOTOPE UPTAKE}

A dose of $1 \mathrm{mCi}$ of $99 \mathrm{~m} \mathrm{Tc}$-albumin in about $1 \mathrm{ml}$ was injected into an antecubital vein in one second. The abdomen was scanned with a Scinticamera gamma camera with diverging collimator (Nuclear Enterprises) interfaced with a data processing system (Computer Corporation of America). The system is based on a PDP-8/1 microcomputer with 8192 words of memory. The site of the placental blood 